\title{
COVID-19 Pandemic Related to Anxiety Disorder Among Communities Using Public Transport at Addis Ababa, Ethiopia, March 2020: Cross-sectional Study Design
}

\section{Chalachew Kassaw ${ }^{1}$ • Digvijay Pandey ${ }^{2}$ (D)}

Received: 15 September 2020 / Revised: 1 November 2020 / Accepted: 16 November 2020 /

Published online: 4 January 2021

(c) Springer Nature Switzerland AG 2021

\begin{abstract}
Coronavirus disease (COVID-19) continues to be the World Health Organization's focus for action for managing the spread and mortality. Public transport is mostly used in the city to serve many people at a time. It was a risky area for contracting the infection. The mental health of a community is vital to promote their immunity and day-to-day activities of humans. This study aimed to determine general anxiety disorder among public transport users in relation to new coronavirus pandemic during the initial phase at Addis Ababa, Ethiopia. The cross-sectional study design was conducted from March 15 to 25, 2020, using a stratified sampling technique. The structured interview was used to collect information on demographic data and general anxiety disorder for the past 2 weeks related to COVID-19. Generalized Anxiety Disorder-7 was used to assess the outcome variable, and logistic regression analysis at a 95\% confidence interval, $p<0.05$, was used to predict variables associated with the outcome variable. This study enrolled 420 respondents who were using public transport in Addis Ababa. Out of the total, 30.7\% of respondents had general anxiety disorder, and being female, daily labor, more than three family sizes, and no face mask use were variables associated with the outcome variable $(p<0.05)$. One third of the respondents experienced general anxiety disorder in response to the pandemic. This study finding indicates that there is a need for immediate mental health crisis intervention at public transport users especially on those identified groups of peoples.
\end{abstract}

Keywords Public transport users · COVID-19 - General anxiety disorder - Addis Ababa · Ethiopia

Chalachew Kassaw

1234berekassa@gmail.com

Digvijay Pandey

digit11011989@gmail.com

1 Department of Psychiatry, College of Health Science, Dilla University, P.O. Box 419, Dilla, Ethiopia

2 Department of Technical Education, IET, Dr. A.P.J. Abdul Kalam Technical University, Uttar Pradesh, Lucknow 226021, India 


\begin{tabular}{ll}
\multicolumn{2}{l}{ Abbreviations } \\
AOR & Adjusted odd ratio \\
CI & Confidence interval \\
COR & Crude odd ratio \\
COVID-19 & Coronavirus disease 2019 \\
ETB & Ethiopian birr \\
GAD & General anxiety disorder \\
KAP & Knowledge, awareness, and practice
\end{tabular}

\section{Introduction}

Public transport is an essential part of urban life, and many peoples in lower level income countries are using it to meet their daily needs. Traveling is a natural need of a human to fulfill their basic activities and needs of daily life (Lopez, 2003). The 2019 coronavirus disease (COVID-19) pandemic is a global concern after its first outbreak in Wuhan city of China and the largest by its coverage and death as compared to 2012, the first epidemic in Saudi Arabia (Mahase, 2020).

The virus continues to spread and was declared as an emergency health condition by the World Health Organization. Currently globally, there are 30,367,850 confirmed cases, 950,821 deaths, and 22,052,941 recoveries, and in Ethiopia, there are 1060 deaths (Cucinotta and Vanelli, 2020).

The virus is too contagious and transmits to humans through respiratory droplets, physical contact, and surface contact, and patients were both symptomatic and asymptomatic. The incubation period of the virus was a 1-week (2-14 days) period, which was a base for the quarantine period of duration for suspected cases and confirmed cases (WHO, 2020; Rehman, 2020).

Ethiopian Ministry of Health works on controlling the spreading virus at transport services, such as decreasing the number of passengers at each transport type to the extent of $50 \%$ of the previous number of passengers and legal punishment among those who were not using a face mask. Another important measure was the use of sanitizer during the entry to bus and daily disinfecting the seats of each passenger (Shigute, 2020).

Social distancing is the principal way of prevention method to control the transmission from human to human, including a 1-m distance of talk and staying away from people. However, these measures have a significant impact on passengers using different types of public transport for achieving their day-to-day activities ( Beam and Kim, 2020; Culp, 2020)

As per my knowledge, there are no published studies done in low- and middle-level countries about public transport user's level of anxiety in response to the COVID-19 pandemic. Therefore, the purpose of this study was to determine the magnitude of general anxiety disorder and its associated factor among public transport users in relation to the new COVID-19 pandemic. This study result might be used as a reference for future studies and also for generating appropriate mental health crisis management among communities using public transport in response to the pandemic. 


\section{Methods and Materials}

This community based cross-sectional study design was conducted from March 15- 25, 2020, at Addis Ababa city, the capital city of Ethiopia, and most cases were confirmed. In the city, there are 300 buses were giving service for the one-third population of the city ( 2 million people).

\section{Eligibility Criteria}

Inclusion Criteria: All peoples age $18+$ and living in the city.

Exclusion Criteria: Respondents who were not able to respond to the interview (unable to hear and respond with the asked language, hearing problem, acutely or severely ill).

\section{Sample Size Calculation}

To calculate the sample size, we used a single proportion formula of a cross-sectional study design. The proportion value $(\mathrm{P})$ from the previous study done in China on the same epidemic $(53.8 \%)$ (Wang, 2020) was taken for the calculation.

$\mathrm{P}=0.54 \%, \mathrm{q}=1-\mathrm{p}, 0.46$.

where $n=$ required sample size, $n=\mathrm{Z}(\alpha / 2) 2 \mathrm{pq} / \mathrm{d} 2, p=0.54$

$=(1.96)(1.96)(0.54)(0.46) /(0.05)(0.05)$

$=382$

where $Z$ is the reliability coefficient at a $95 \%$ confidence interval (1.96)

$W$ (margin of error) $=0.05$

$N$ non-response rate $10 \%=38$

The total sample size was $382+38=420$

\section{Sampling Technique and Procedure}

A stratified sampling technique was used to select the bus from the three types of bus (Anebessa bus, Sheger bus, and Higer bus). "Anebessa" bus was serving for 100 people and travel up to $6 \mathrm{~km}$, "Sheger bus" was serving 50 people and travel up to $4 \mathrm{~km}$, and "Higer bus" was serving for 40 people and travel up to $2 \mathrm{~km}$. Proportionate stratification formula, $n h=(N h / N) \times n(n h=$ required sample, $N h=$ total sample size of each stratum, $N=$ total population size, $n=$ total sample size), was used to select the required number of the sample from each selected bus. Finally, simple random sampling with a lottery method was used to select each respondent from each selected bus. The ticket number was used as the sampling frame for the study.

$n$ (Anebessa bus) $=N$ (Anebessa bus total population stratum)/total population size $\times$ sample size $=(300 / 570) \times 420=221$

$n($ Sheger bus $)=N($ Sheger bus total population the stratum $) /$ total population size $\times$ sample size $=(150 / 570) \times 420=111$

$n$ (Higer bus $)=N($ Higer bus total population the stratum $) /$ total population size $\times$ sample size $=(120 / 570) \times 420=88($ Fig. 1$)$. 


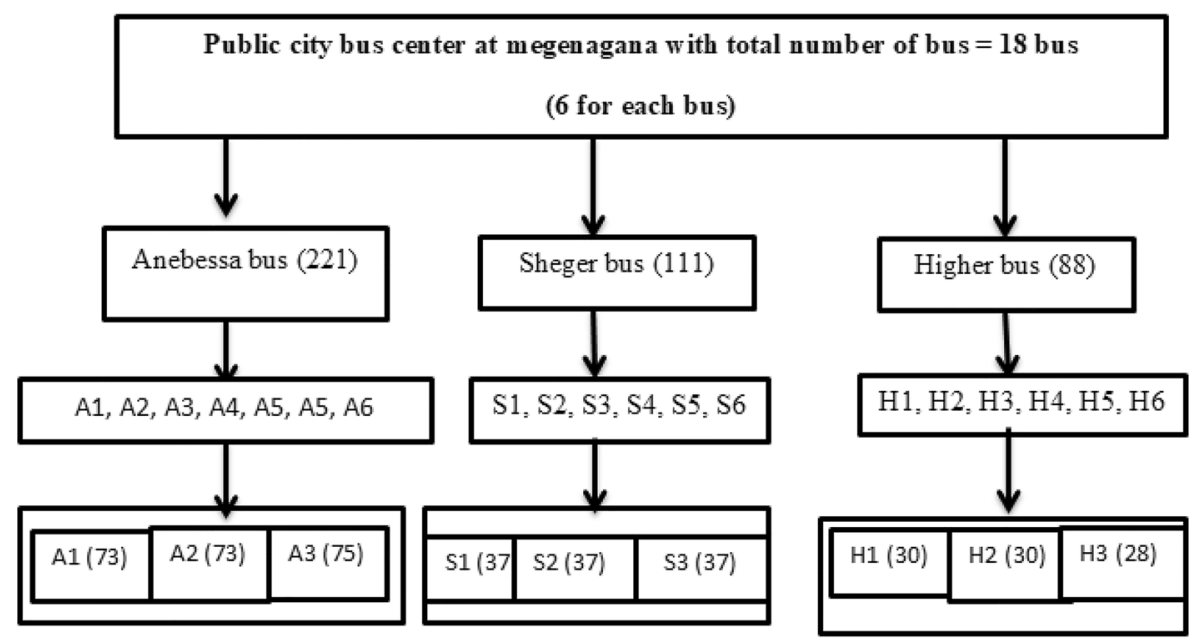

Fig. 1 Diagrammatic scheme of stratified sampling among respondents using public transport $(N=420)$

\section{Data Collection Instruments}

All questionnaires were translated into Amharic and then to English, and finally, the Amharic version of the questioner was used for data collection.

General Anxiety Disorder: The first part of the questioner was GAD-7 (Generalized Anxiety Disorder-7) scale to assess the subject's anxiety symptoms. The GAD-7 assessment tool was validated and used in previous Ethiopia studies. It has seven items used to assess the frequency of anxiety symptoms over the past 2 weeks on a 4-point Likert scale ranging from 0 (never) to 3 (nearly every day) and ranging from 0 to 21 , and score $>9$ scores defined as had general anxiety disorder (Maideen et al., 2015).

Current Knowledge, Attitude, and Practice (KAP) About the Coronavirus. It was a 12-item questioner used to measure the knowledge, attitude, and practice of respondents towards COVID-19. During pretest, the Cronbach's alpha for this tool was 0.83 (Zhong et al., 2020).

\section{Study Variables}

Dependent Variable: General anxiety disorder.

Independent Variables: Age, sex, educational status, occupational status, family size, having a child less than five years, and knowledge, attitude, and practice about the coronavirus.

\section{Data Collection Procedures}

The carefully prepared questioner and training manual was used for data collection and training for data collectors about the aims of the study, formats the questionnaire, how to interview, and gather data from the respondents. The issues of privacy and confidentiality 
were discussed during the training manual. The structured interviews were administered for each respondent and collected all the required information.

\section{Data Processing and Analysis}

Data was entered into the Epi-Data 3.4 software package and exported to the Statistical Package for Social Science version 22. Descriptive statistics (frequencies and percentages) and cross-tabulation calculated to see the distribution of study variables among study participants. The logistic regression analysis $(5 \% \mathrm{CI}, p<0.05)$ was used for determining the predictors of the outcome variable.

\section{Result}

The mean age onset of the respondents was 32 years of age, and half of respondents had more than three family sizes; the average monthly income was 1000 ETB (Table 1).

\section{Knowledge, Attitude, and Practice (KAP) About Coronavirus}

More than two thirds of the respondents were not using face mask to prevent the COVID19 pandemic transmission (Table 2).

Table 1 Socio-demographic characteristics results of respondents using public transport living in Addis Ababa, Ethiopia $2020(N=420)$

\begin{tabular}{|c|c|c|c|}
\hline Variable & Category & $\begin{array}{l}\text { Fre- } \\
\text { quency } \\
(n=420)\end{array}$ & Percentage (\%) \\
\hline \multirow[t]{2}{*}{ Sex } & Male & 181 & $43 \%$ \\
\hline & Female & 239 & $57 \%$ \\
\hline \multirow[t]{4}{*}{ Marital status } & Single & 190 & $45.2 \%$ \\
\hline & Married & 94 & $22.3 \%$ \\
\hline & Divorced & 76 & $18 \%$ \\
\hline & Widowed & 60 & $14.2 \%$ \\
\hline \multirow[t]{3}{*}{ Educational status } & Primary & 63 & $15 \%$ \\
\hline & Secondary & 120 & $28.5 \%$ \\
\hline & More than secondary & 237 & $56.5 \%$ \\
\hline \multirow[t]{4}{*}{ Occupation } & Daily labor & 178 & 42.3 \\
\hline & Private job & 122 & 29 \\
\hline & Student & 85 & 20.2 \\
\hline & Unemployed & 35 & 8.3 \\
\hline \multirow[t]{3}{*}{ Family size } & One & 49 & $11.6 \%$ \\
\hline & Two & 165 & $39.2 \%$ \\
\hline & Three and above & 206 & $49 \%$ \\
\hline
\end{tabular}




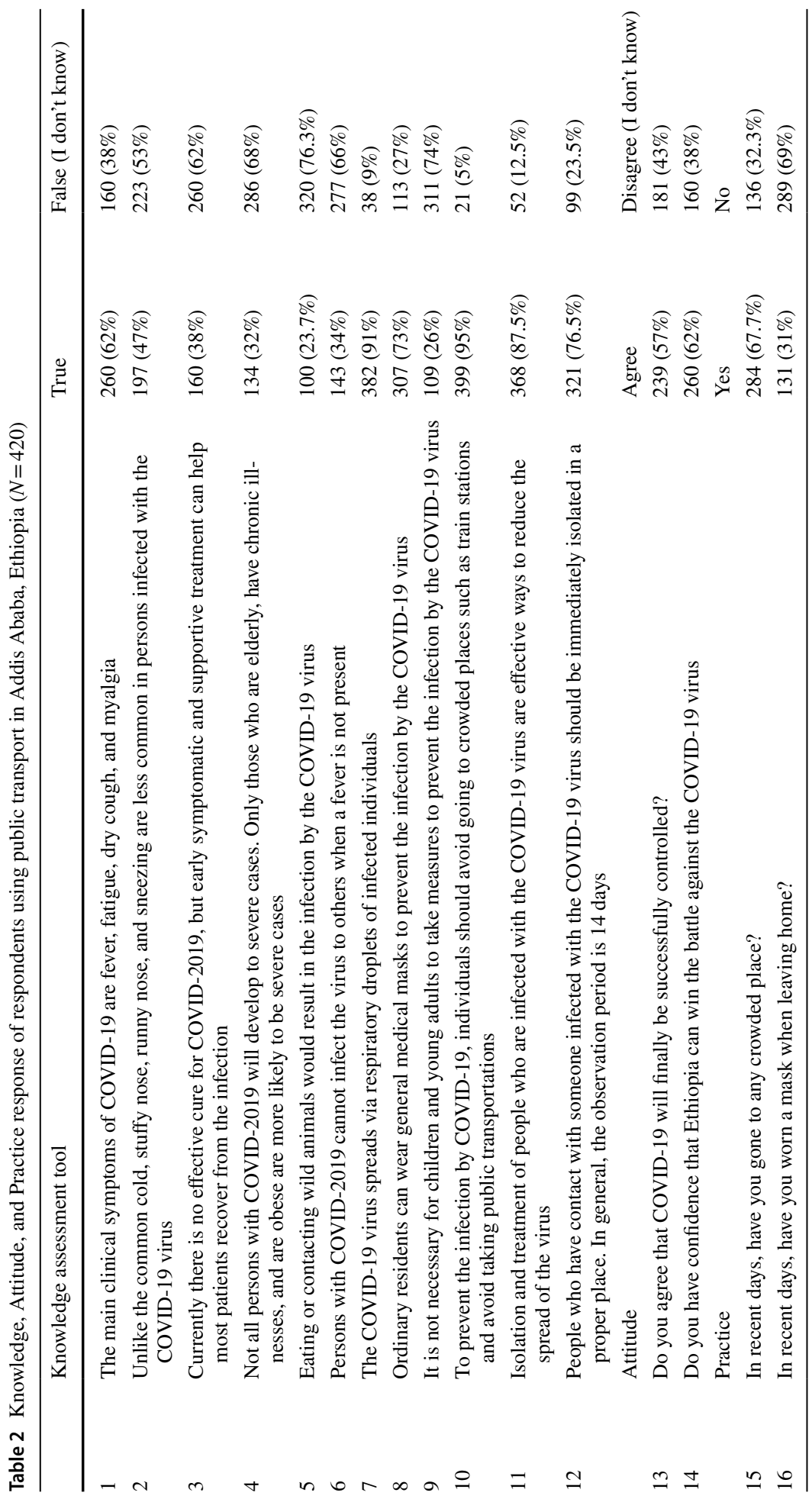


Table 3 The predictors of the outcome variable among respondents who were using public transport at Addis Ababa, Ethiopia, $2020(N=420)$

\begin{tabular}{|c|c|c|c|c|c|}
\hline \multirow[t]{2}{*}{ Variables } & \multirow[t]{2}{*}{ Category } & \multicolumn{2}{|c|}{$\begin{array}{l}\text { Generalized } \\
\text { anxiety disor- } \\
\text { der (GAD) }\end{array}$} & \multirow[t]{2}{*}{ Adjusted odds ratio (AOR) } & \multirow[t]{2}{*}{$p$ value } \\
\hline & & Yes & No & & \\
\hline \multirow[t]{2}{*}{ Sex } & Male & 81 & 100 & 1 & \\
\hline & Female & 179 & 60 & $3.68(2.43,5.57)$ & $0.02 *$ \\
\hline \multirow[t]{4}{*}{ Marital status } & Single & 70 & 120 & 1 & \\
\hline & Married & 34 & 60 & $1.03(0.62-1.72)$ & 0.29 \\
\hline & Divorced & 34 & 42 & $0.72(0.42-1.24)$ & 0.24 \\
\hline & Widowed & 24 & 36 & $0.88(0.48-1.59)$ & 0.16 \\
\hline \multirow[t]{3}{*}{ Educational status } & Primary & 30 & 33 & $1.20(0.48-1.47)$ & 0.18 \\
\hline & Secondary & 44 & 76 & $0.58(0.38-0.89)$ & $0.01 *$ \\
\hline & More than secondary & 123 & 114 & 1 & \\
\hline \multirow[t]{4}{*}{ Occupation } & Daily labor & 123 & 55 & $3.78(1.78-8.06)$ & $0.001 * *$ \\
\hline & Private job & 57 & 65 & $1.29(0.6-2.77)$ & 0.18 \\
\hline & Student & 35 & 50 & $1.18(0.53-2.66)$ & 0.12 \\
\hline & Unemployed & 13 & 22 & 1 & \\
\hline \multirow[t]{3}{*}{ Number of family size } & One & 16 & 23 & 1 & \\
\hline & Two & 74 & 91 & $1.17(0.58-2.37)^{*}$ & 0.21 \\
\hline & Three and above & 144 & 62 & $3.34(1.65-6.75)^{* *}$ & $0.001 * *$ \\
\hline \multirow[t]{2}{*}{ Wearing mask } & No & 196 & 93 & $4.47(2.87-6.95)^{*}$ & \\
\hline & Yes & 42 & 89 & 1 & $0.001 * *$ \\
\hline
\end{tabular}

$1=$ Reference. $* 00.05 ; * p \leq 0.01 * *$

\section{Magnitude of General Anxiety Disorder}

Out of all respondents enrolled in the study, 128 (30.7\%) of them developed clinically significant generalized anxiety disorder (scored $>9 / 21$ ) as a result of the current pandemic (COVID-19).

\section{Predictors of the Outcome Variable}

Variables associated with the outcome variable during multivariant logistic regression at 95\% CI were female gender, daily labor, no face mask use, and more than three family sizes (Table 3).

\section{Discussion}

This study aimed to measure the magnitude of general anxiety disorder among public transport users during the initial phase of the pandemic, and $128(30.7 \%)$ of them developed generalized anxiety disorder in response to the new COVID-19. 
This study finding was lower than the community studies done in China, 53.8\% (Wang, 2020). It might be due to the difference in literacy about coronavirus, income for using personal protective equipment, and the tool used to measure current mental status (DASS-21).

This study result was higher than the studies conducted among health professionals in India (25.3\%) (Wilson et al., 2020) and Saudi-Arabia (7.3\%). The public transport users had a chance of being worried and stressed due to the susceptibility for physical contact and inadequate access to personal protective materials, including sanitizers and handwashing facilities, which all result in fear of contracting the disease.

According to this study finding, being female had $3.68(2.43,5.57)$ times more likely to experience a general anxiety disorder, which was similar to the study done in Spain (Gómez-Salgado et al., 2020) and India (Ahmad et al., 2020). Females have frequent traveling history and responsibility for achieving the day-to-day activities outside the home and contribute to the risk of contracting infection due contact with different people by bus.

This study identified that those with daily labor occupation had 3.78 (1.78-8.06) times more likely to develop GAD as compared with other groups of jobs and evidenced in Russia (Kartseva and Kuznetsova, 2020). Daily laborers have a high susceptibility contacting infection due to their job situation of close contact with co-workers. Besides, they were not able to buy face masks and other safety preventive measures for the prevention of self and their family.

The current family size of respondents has an impact on the development of general anxiety disorder, and those with more than three family sizes had 3.34 (1.65-6.75) times more likely to develop GAD, which was supported by the study done in India (Ahmad et al., 2020). As the number of family size increases, their chance of contact with different people also increases, which contributes to getting infected due to its contagious nature, and their worry becomes very significant for fear of contracting the infection.

The last determinant variable for GAD was current face mask use, and those who did not use a face mask for prevention had 4.47 times (2.87-6.95) more likely to develop a general anxiety disorder, which was similar to the study done in China (Ying et al., 2020). The use of a face mask enhances awareness, knowledge, and information about prevention measures, which contribute to the feeling of psychological preparedness to prevent themselves and their families.

\section{Conclusions}

The current study found that one thirds of the respondents had general anxiety disorder. The predictors for the outcome variable were being female, daily labor, more than three family sizes, and no face mask use.

Therefore, public transport users' needs immediate mental health intervention from responsible government and private health sector organizations to reassure the passenger's psychological health. The government should provide supportive preventive materials such as face mask, glove soap, and alcohol for public transport users, especially for those with more than three family size and daily labor. The public transport service providers should prepare a relaxing, comfortable, and allocate enough number of the bus for the passengers to serve effectively through keeping safety measures of the prevention. The mental health professional should teach via accessible social media about how to cope with the current pandemic and lifestyle measures, which are helpful to increase immunity, including exercise, diet, and regular sleep.

Acknowledgments I would like to thank the clients who participated in the study, Addis Ababa transport office and Dilla University. 
Author contributions CK carried out the manuscript from its conception, analysis, and interpretation of data and drafted the manuscript.

Funding This study was funded by Dilla University.

\section{Compliance with Ethical Standards}

Conflict of Interest The authors declare that they have no conflicts of interest.

Ethics Approval Ethical clearance was gained from the ethical review board of Dilla University, and informed consent was obtained from the study participants. The confidentiality and privacy of the information obtained from respondents were ensured.

Consent to Participate Oral informed consent was obtained from the respondents from each participant before the actual data collection.

Availability of Data and Materials The datasets are available from the corresponding author on a reasonable request.

\section{References}

Ahmad, A., Rahman, I., \& Agarwal, M. (2020). Early psychosocial predictors of mental health among Indians during coronavirus disease 2019 outbreak. Journal of Health Sciences, 10(2), 147-156.

ARehman, S., Majeed, T., Ansari, M. A., \& Al-Suhaimi, E. A. (2020). Syndrome resembling Kawasaki disease in COVID-19 asymptomatic children. Journal of Infection and Public Health.

Beam, C. R., \& Kim, A. J. (2020). Psychological sequelae of social isolation and loneliness might be a larger problem in young adults than older adults. Psychological Trauma: Theory, Research, Practice, and Policy, 12(S1), 58-62.

Cucinotta, D., \& Vanelli, M. (2020). WHO declares COVID-19 a pandemic. Acta Biomedica, 91(1), 157160. https://doi.org/10.23750/abm.v91i1.9397

Culp, W. C. (2020). Coronavirus disease 2019. A \& A Practice, 14(6), e01218. https://doi.org/10.1213/ xaa.0000000000001218

Gómez-Salgado, J., Domínguez-Salas, S., Romero-Martín, M., Ortega-Moreno, M., García-Iglesias, J. J., \& Ruiz-Frutos, C. (2020). Sense of coherence and psychological distress among healthcare workers during the COVID-19 pandemic in Spain. Sustainability, 12(17), 68-72. https://doi.org/10.3390/su12176855

Kartseva, M. A., \& Kuznetsova, P. O. (2020). The economic consequences of the coronavirus pandemic: which groups will suffer more in terms of loss of employment and income? Population and Economics, 4(2), 26-33. https://doi.org/10.3897/popecon.4.e53194

López, J. C. (2003). Means of transportation. Nature Reviews Neuroscience, 4(6), 431-431. https://doi. org/10.1038/nrn1149

Mahase, E. (2020). China coronavirus: what do we know so far? BMJ (Clinical Research Ed.), 368(January), m308. https://doi.org/10.1136/bmj.m308

Maideen, S. F. K., Sidik, S. M., Rampal, L., \& Mukhtar, F. (2015). Prevalence, associated factors and predictors of anxiety: a community survey in Selangor, Malaysia. BMC Psychiatry, 15(1), 1-12. https:// doi.org/10.1186/s12888-015-0648-X

Shigute, Z., Mebratie, AD., Alemu, G., Bedi, A., (2020). Containing the spread of COVID-19 in Ethiopia. Journal of global health, 10(1).

Wang, C. (2020). Ethiopian religious beliefs. Int. J. Environ. Res. Public Healt, 17, 1729. https://doi. org/10.3390/ijerph17051729

Wilson, W., Raj, J. P., Rao, S., Ghiya, M., Nedungalaparambil, N. M., Mundra, H., \& Mathew, R. (2020). Prevalence and predictors of stress, anxiety, and depression among healthcare workers managing COVID-19 pandemic in India: A nationwide observational study. Indian Journal of Psychological Medicine, 42(4), 353-358. https://doi.org/10.1177/0253717620933992

World Health Organization. (2020) Modes of transmission of virus causing COVID-19: implications for IPC precaution recommendations: scientific brief, 29 March 2020. 
Ying, Y., Kong, F., Zhu, B., Ji, Y., Lou, Z., \& Ruan, L. (2020). Mental health status among family members of health care workers in Ningbo, China during the Coronavirus Disease 2019 (COVID-19) outbreak: a Cross-sectional Study. BMC Psychiatry, 20(379), 1-10. https://doi.org/10.1186/s12888-020-02784-

Zhong, B. L., Luo, W., Li, H. M., Zhang, Q. Q., Liu, X. G., Li, W. T., \& Li, Y. (2020). Knowledge, attitudes, and practices towards COVID-19 among Chinese residents during the rapid rise period of the COVID-19 outbreak: a quick online cross-sectional survey. International Journal of Biological Sciences, 16(10), 1745-1752. https://doi.org/10.7150/ijbs.45221

Publisher's Note Springer Nature remains neutral with regard to jurisdictional claims in published maps and institutional affiliations. 